\title{
城市生态系统修复研究进展
}

\author{
李 锋 ${ }^{1,2}, *$, 马 远 $^{1,2}$
}

1 清华大学建筑学院景观学系, 北京 100084

2 清华大学建筑学院生态修复研究中心, 北京 100084

\begin{abstract}
摘要:城市生态系统是社会-经济-自然复合生态系统。城市生态系统修复的实质是协调好城市复合生态系统的自然过程、经济 过程和社会过程之间的关系,促进复合生态系统的各方面协调高效可持续发展。以城市绿地、城市湿地、城市废弃地三类主要 的城市生态空间为对象, 论述了城市生态系统修复的研究进展, 提出当前城市生态系统修复存在以人工修复技术为主、自然修 复不足、机理和量化研究缺乏、理论和应用脱节、管理机制不健全、复合生态系统理论体现不足等问题。梳理了当前城市生态系 统修复的研究热点,包括城市生态系统修复机理、城市生态资产与生态系统服务、城市生态系统质量和健康、问题导向的生态修 复、面向人类福祉的生态修复、生态修复多学科融贯, 以及新方法和新技术的应用等几个方面。提出了城市生态修复与管理的 相关对策和建议,可为我国城市生态系统修复的研究和实践提供参考。
\end{abstract}

关键词:城市生态系统;复合生态系统;生态修复;生态系统服务;生态管理

\section{Research progress of urban ecosystem restoration}

\author{
LI Feng $^{1,2, *}$, MA Yuan ${ }^{1,2}$ \\ 1 Department of Landscape Architecture, School of Architecture, Tsinghua University, Beijing 100084, China \\ 2 Research Center for Ecological Restoration, School of Architecture, Tsinghua University, Beijing 100084, China
}

\begin{abstract}
Urban ecosystem is a kind of complex social-economic-natural ecosystem. The essence of urban ecosystem restoration is to coordinate the relationship among the natural process, economic process and social process of the urban complex ecosystem, and promote the coordinated and efficient development of all aspects of the complex ecosystem. This paper takes urban green space, urban wetland, urban wasteland, three main types of urban ecological space, as the objects, and discusses the research progress of urban ecosystem restoration. Then we point out that the current urban ecosystem restoration has some questions such as too much artificial restoration and lacking of natural restoration, the lack of mechanism and quantitative research, the disconnection between theory and application, the imperfect management mechanism, and the weakness of complex ecosystem theory application, and so on. This article reviews the current research hotspots of urban ecosystem restoration, including restoration mechanism of urban ecosystem, urban ecological asset and ecosystem services, urban ecosystem quality and health, ecological restoration resulted from urban problems, ecological restoration oriented to human welfare, multidisciplinary integration of ecological restoration, and application of new methods and technologies. Finally, the paper puts forward the relevant countermeasures and suggestions of urban ecological restoration and management, which can provide references for the research and practice of urban ecosystem restoration in China.
\end{abstract}

Key Words : urban ecosystem; complex ecosystem; ecological restoration; ecosystem services; ecological management

基金项目: 国家自然科学基金重点项目 (71734006); 国家重点研发计划项目(2016YFC0502800)

收稿日期: 2020-01-02; 网络出版日期:2021-07-24

*通讯作者 Corresponding author.E-mail: feng_li@ tsinghua.edu.cn 
20 世纪 80 年代初,马世骏和王如松从生态学的观点出发,提出城市生态系统是以人的行为为主导、自然 环境为依托、资源流动为命脉、社会体制为经络的社会-经济-自然复合生态系统 ${ }^{[1]}$ 。城市生态系统修复是基 于复合生态系统理论的共轭生态修复,其核心就是要调节好以水、土、气、生、矿为主体的自然生态过程, 以生 产、流通、消费、还原、调控为主流的经济生态过程和以人的科技、体制、文化为主线的社会生态过程在时、空、 量、构、序范畴的生态耦合关系,推进以整体、协同、循环、自生为基础的生态规划、生态工程与生态管理的技术 体系,在保育生态活力的前提下,实现社会经济的高速协调发展。其基本宗旨是从观念转型、体制改革和技术 创新人手, 修复、涵养、强化区域社会生态、经济生态和自然生态系统服务, 促进人与自然的协同进化, 使得城 市生态系统的各个方面都修复到结构合理、功能高效、关系和谐的状态。

城市绿地、湿地、废弃地组成了城市最主要的生态空间。长期以来, 众多学者从城市绿地、湿地和废弃地 的角度人手, 对城市生态系统修复开展了大量研究, 涵盖生态系统修复的工程技术、调查、评估、规划、管理等 多个方面,取得了丰富的研究成果。

\section{1 城市生态系统修复研究进展}

\section{1 城市绿地生态系统修复研究进展}

本文城市绿地是广义的概念, 一般是指城市及城市周边的园林绿地、城市森林等, 还可包含都市农田、立 体绿化等多种形式 ${ }^{[2-3]}$ 。西方发达国家在经历了 “先污染后治理”工业模式之后, 环境遭到严重破坏, 最先认 识到城市绿地对生态环境的改善作用。19 世纪末,奥姆斯特德等人把数个公园连在一起,形成了景观优美的 波士顿公园体系; 莫斯科通过 20 世纪 30 年代的“绿色城市” 绿地系统改造, 发展成为花园城市; 我国在 20 世 纪 70 年代提出了城市绿地“连片成团, 点线面结合” 的方针, 大幅促进了城市绿化的发展 ${ }^{[4]}$ 。目前, 随着城市 化和城市绿化建设的发展, 人们对城市绿地的认知进一步加强, 其在改善城市生态环境、提升人居生活质量方 面的价值已得到公认。城市绿地已被视为城市的绿色基础设施, 目前针对城市绿地的生态系统修复开展了大 量研究,主要聚焦于以下方面:

\subsection{1 城市绿地的生态系统服务}

一般认为, 绿地具有支撑、供给、调节、文化 4 大类生态系统服务 ${ }^{[5]}$ 。对城市绿地生态系统服务的研究主 要集中于调节功能和文化功能两大类。其中, 调节功能有涵养水源、调节径流、固碳释氧、调节小气候等; 文化 功能主要体现在美学、精神、教育、娱乐等方面的功能和价值 ${ }^{[6]}$ 。随着城市发展、人们认知水平提高以及研究 方法的进步, 城市绿地生态系统服务的内涵也在不断丰富, 研究内容和发展趋势主要体现在以下方面: (1)重视 城市绿地对城市这一独特生态环境的作用及相互影响, 如改善城市热岛效应、减缓雨洪灾害、降低噪音、滞留 空气颗粒物、吸收有毒气体、土壤重金属等方面 ${ }^{[7-8]}$; 2)关注城市绿地对居民生活的影响,如景观游慜、防灾避 灾、与人类身心健康、幸福感、满意度等的关系 ${ }^{[9-10]}$; (3)对城市绿地结构和功能相互关系的研究逐步深人, 主要 是绿地的配置方式、树种选择、最小适宜面积等方面 ${ }^{[11-12]}$; (4)研究趋向于精细化, 如针对海绵城市绿地、棕地 修复等具有特定用途绿地的研究 ${ }^{[13-14]}$; (5)定性研究向定量研究转变; 6 重视对城市绿地生物多样性的研究; (7)研究的区域逐步扩大,已经从单一或少数绿地扩展到区域尺度研究 ${ }^{[15-16]}$ 。

\subsection{2 城市绿地的空间格局}

当前,城市绿地已成为城市生态基础设施的重要部分,其布局、规划也作为城市空间规划的重要内容得到 了应有的重视。随着景观生态学、城市规划等学科理论的深人, 以及 RS、GIS 等空间数据和分析技术的发展, 城市绿地的空间格局和演变过程成为了研究热点, 深人探讨城市绿地格局和过程的量化关系成为了可能。目 前对城市绿地空间格局研究主要从绿地格局与生物多样性、绿地格局与城市生态环境、绿地格局与居民使用 和健康、绿地格局与城市的协调发展等方面开展 ${ }^{[17-20]}$ 。

\subsection{3 城市绿地的生态管理}

城市绿地的生态管理是提升绿地系统质量, 优化生态系统服务的重要途径。目前对于城市绿地管理的研 
究主要有以下方面: (1)城市绿地的保护修复和开发利用。通过建立森林公园、自然保护区等多种保护地形式,

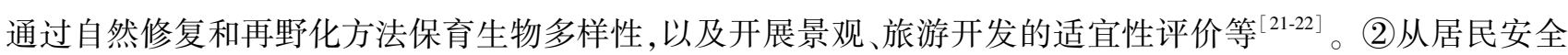
角度出发,探讨绿地空间结构和安全的关系、城市树木管护措施对安全的影响等 ${ }^{[23]}$; (3) 从提升绿地生态系统 健康的角度出发, 开展绿地的健康状况评价 ${ }^{[23]}$; (4)城市绿地的管理提倡近自然营造、乡土树种选用、绿地土壤 保育等 ${ }^{[24]}$ 。此外,近年来,许多研究从社会学角度研究城市绿地的空间布局公平性管理, 以及公众参与机制 等的研究 ${ }^{[25-26]}$ 。

\section{2 城市湿地生态系统修复研究进展}

湿地被称为地球之肾, 其生态价值早已得到公认, 国内外关于湿地开展了很多研究。相比之下, 人们对城 市湿地的关注比较晚。在国际上,2008 年召开的《湿地公约》第十届大会首次关注 “湿地与城市化”, 此后直 到 2012 年才正式提出了城市和城郊湿地的概念 ${ }^{[27]}$ 。

相比于自然湿地,城市湿地由于地处城市及周边,与人类生产、生活具有更加密切的联系。在城镇化的影 响下,城市湿地面积呈现出更明显的锐减态势。据统计,美国的城市湿地在 20 世纪减少了 $50 \%$, 北京市仅 1980 年至今城市湿地面积已缩减一半,武汉市从 1950 年到 1998 年湖泊面积减少了 $90 \%$ 以上 ${ }^{[28]}$ 。此外, 城市 湿地的水质及水文过程受城市环境影响强烈 ${ }^{[29-30]}$, 水质污染、生态系统功能退化等问题十分突出。因此, 保 护和修复城市湿地生态系统, 是当前需要研究的重要课题,目前的研究主要集中于以下方面:

\subsection{1 城市湿地的生态系统服务}

湿地生态系统服务的研究主要有功能的评估和价值的核算, 是开展城市湿地生态修复和管理工作的重要 基础。围绕城市湿地的生态系统服务,国内外学者开展了大量研究。早期的研究主要沿用自然湿地生态系统 服务的分类体系和核算方法。影响较广泛的分类体系是 2005 年联合国千年生态系统评估,该体系梳理了湿 地的供给、调节、文化、支持四大类功能,并向下分为食物供给、原材料供给、水质净化、调蓄洪水、土壤保持、固 碳释氧、提供生物栖息地、涵养水源、休闲娱乐等 17 项生态系统服务 ${ }^{[5]}$ 。目前,湿地生态系统服务的研究方法 主要是利用卫星遥感和地理信息系统技术,通过遥感影像、统计数据、社会调查等途径,评估生态系统服务的 功能和价值, 评价方法主要有能值法、物质量法、价值量法等方法体系 ${ }^{[31]}$ 。由于城市湿地与自然湿地间存在 明显的差异性,自然湿地的分类体系难以全面反映城市湿地的生态系统服务。有学者认为和自然湿地相比, 城市湿地供给功能弱化, 但是在城市安全、人类生活方面的服务更加明显 ${ }^{[32]}$ 。因此, 近年来, 许多研究开始着 眼于城市湿地对城市和居民的生态系统服务, 如缓解热岛效应、吸纳空气颗粒物、自然教育、居民幸福指数、房 价等方面 ${ }^{[33-39]}$ 。

\subsection{2 城市湿地的生态修复技术}

城市湿地与自然湿地相比,其生态系统破坏具有不同的特点: 1) 建设导致的湿地破碎化;2) 硬化地表和 沟渠等改变了径流过程; 3 )大量生产生活污染物危害湿地水环境 ${ }^{[29-30]}$ 。目前针对城市湿地的生态修复方法 和技术的研究主要集中于城市湿地的格局优化、水资源配置、水文过程调节、水质净化、生态系统调控等 方面 ${ }^{[29-30]}$ 。

此外, 人工湿地在城市湿地生态修复中的作用越来越大,已成为了城市湿地的一个重要组分。人工湿地 是一种集合了植物、基质、微生物共同作用的生态污水处理系统 ${ }^{[0]}$, 根据水面位置可分为表流型和潜流型湿 地 ${ }^{[41]}$, 具有成本低廉、管理简便的特点 ${ }^{[42]}$ 。目前关于人工湿地的研究多集中于处理农业点面源污染、生活污 水处理、雨水处理等方面 ${ }^{[43-46]}$, 研究内容主要有植物的选择、基质的选择、处理工艺流程等 ${ }^{[42]}$ 。早期的多数研 究都认为人工湿地是结构和功能比较单一的一种功能性湿地 ${ }^{[47]}$, 近年来许多研究开始关注基于自然-经济-社 会复合生态系统理念的复合型人工湿地, 在人工湿地中结合了科普教育、景观游憩、生物栖息地等功 能 ${ }^{[45,48-49]}$, 取得了很多成果, 如成都的活水公园就是将污水处理的工艺流程与景观游憩和科普教育相结合的 一个成功尝试 ${ }^{[50]}$ 。

\subsection{3 城市湿地的保护和管理}

随着人类经济社会的发展,湿地保护和管理的理念也处在不断变化之中。总体来看,是一条从开发到保 
护的发展路径。以美国为例, 美国的湿地保护政策经历了湿地开发期、政策转型期、“零净损失期”三个阶 段 ${ }^{[51]}$ 。在城市复合生态系统背景下,城市湿地的主要管理目标是: 保护和修复湿地的结构和功能、推动社会 发展、实现湿地资源的可持续利用 ${ }^{[51]}$ 。目前, 国内外对于城市湿地的管理和保护措施主要有以下方面: 1) 通 过制定相关的法律法规保护城市湿地 $\left.{ }^{[52]} ; 2\right)$ 城市湿地的生态补偿、占补平衡、交易制度等,如美国的“零净损 失”、“湿地银行” 等机制 ${ }^{[53]}$; 3) 建设湿地公园、湿地自然保护区, 加强城市湿地生态系统的保护, 同时合理开 发利用,开展科普教育、休闲游憩等 $\left.{ }^{[54]} ; 4\right)$ 以区域生态格局研究为基础, 将城市湿地纳入到土地利用和总体规 划中, 保护和修复城市湿地的景观格局 ${ }^{[55]}$; 5) 建立持续、动态的城市湿地监测网络和评价体系, 防止湿地退 化 $\left.{ }^{[56]} ; 6\right)$ 推动多元的投资机制, 各级政府、社会资本投人, 以及推动湿地消费等 ${ }^{[57]}$;7) 重视社会监督、公众参 与在城市湿地管理中的作用 ${ }^{[52]}$ 。

\section{3 城市废弃地生态系统修复研究进展}

城镇化过程中,受资源衰竭、产业调整、土地用途变化、生产生活废弃物堆积等多种因素的影响,产生了大 量的城市废弃地, 常见的城市废弃地类型有废弃矿山、工厂、垃圾填埋场等 ${ }^{[58]}$ 。城市废弃地侵占了大量国土 资源, 据 2015 年我国国土统计数据,各类废弃地面积达到近 1000 万 $\mathrm{hm}^{2}$, 其中近 600 万 $\mathrm{hm}^{2}$ 有待复垦; 许多类 型的城市废弃地还存在不同程度的环境污染, 给居民生活带来了严重隐患,甚至造成公害,如美国的腊夫运河 事件等;除此之外,城市废弃地被称为“城市的伤疤”,是城市中“丑婳的斑块”,对城市景观格局和市容环境造 成了不良影响 ${ }^{[59]}$ 。

大量的城市废弃地严重阻碍了城市的健康和可持续发展。城市废弃地的生态系统修复是使城市废弃空 间再度焕发生机、使城市生态环境得到改善的过程,是促使城市复合生态系统中自然、经济、社会三要素协同 发展的必由之路。目前,城市废弃地的生态系统修复研究主要集中于以下方面:

\subsection{1废弃地污染治理技术}

废弃矿山、垃圾填埋场、以及从事污染生产的废弃工厂等许多废弃地类型对生态环境均具有明显的影响， 主要以土壤和地下水污染为主, 常见的污染物类型有重金属、农药化肥类、酸碱盐类、有机物、放射性污染、病 原菌类污染等 ${ }^{[58]}$ 。一般来说, 废弃地污染治理主要有物理、化学、生物途径,如分离、固定、转移、转化、生物降 解等方法。根据污染物处理空间位置的差异可分为原位处理和异位处理。原位修复指不移动受污染的土壤 或地下水,直接在场地发生污染的位置对其进行原地修复或处理; 异位修复技术是对污染的土壤或地下水先 进行挖掘或抽取, 然后搬运或转移到其他场所或位置进行处理 ${ }^{[60]}$ 。原位处理具有节约成本、适宜于深层次污 染、减少对环境的扰动和污染物的暴露等优势, 是当前城市废弃地土壤和地下水污染治理的主要发展方

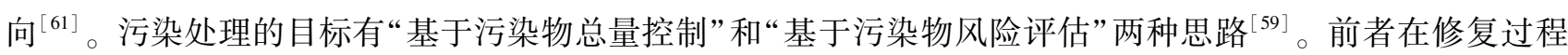
中常面临修复成本极高的限制, 适用于修复简单、污染类型明确的废弃地类型; 后者则是以场地风险控制为目 标, 通过例如用途限制、工程隔离等措施避免特定情景下的风险, 具有经济性和更为广泛的适用性 ${ }^{[62]}$ 。

1.3.2 废弃地生态系统修复和重建技术

由于人类的生产活动,许多废弃地生态系统严重退化。废弃地的生态系统修复主要有人工修复和自然修 复两种思路,对自然修复的研究多集中于修复效果的监测和评价, 而人工修复研究则侧重于开发不同的修复 方法, 如植被修复、动物修复、微生物修复、表层土壤重构、营养物覆盖方法等方面 ${ }^{[63]}$ 。植被修复是生态系统 修复和重建的关键 ${ }^{[64]}$, 围绕植被修复, 目前的研究主要集中在固氮植物、吸附重金属植物、水土保持植物、耐 受性植物等的篮选、配置方法等 ${ }^{[65-73]}$ 。植被的群落演替规律对生态系统修复也具有重要参考作用。还有许 多研究着眼于群落结构、演替动态等方面。如模拟自然群落进行植物修复 ${ }^{[74]}$ 、利用土壤种子库技术修复破坏 的生态系统 ${ }^{[75]}$; 有研究认为废弃地生态系统演替的不同阶段适生植物种类是不同的,应以更高演替阶段物种

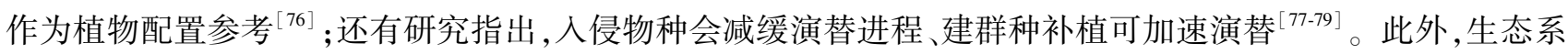
统的修复离不开土壤、水肥等立地条件的改善。一方面是通过边坡固定、工程绿化措施创造立地条件 ${ }^{[80-82]}$, 如挂网喷播、生态植被毯等; 另一方面是通过有机物改良、表层土壤重构、微生物银行等方式改良土壤 ${ }^{[83-85]}$, 
为生态系统健康发展提供基础。

\subsection{3 城市废弃地的生态修复与景观再造模式}

从 20 世纪 90 年代起,国外开始注重通过景观再造模式修复和重建城市废弃地。生态修复的景观再造模 式注重科学技术手段和艺术手法的有机结合,将废弃地改造成为具有丰富内涵和生机的现代景观。我国废弃 地景观再造起步较晚, 以往对于城市废弃地的处理多以环境安全和生态环境改善作为目标。随着国外修复生 态学、现代景观设计思想的传人,我国开始关注废弃地生态修复的景观再造模式。一般来说,城市废弃地的再 利用方式主要有景观旅游用地、居住或商业用地、新型都市工业用地、农业用地等类型 ${ }^{[86]}$ 。但是越来越多的 城市废弃地通过生态修复和景观再造转化成为城市公共景观空间, 原因主要有: 景观再造费用较低、周期短; 可以应对不稳定场地条件, 如水质、地质隐患、潜在的污染等; 使用灵活, 既可作为永久场地, 又可作为临时过 渡场地 ${ }^{[59]}$ 。除此之外, 景观再造模式不仅关注生态修复和景观风貌的再生, 还重视历史文化和场地精神, 使 场地的历史、记忆、土地感知得以再生并传承, 是一种重要的自然-经济-社会复合生态修复途径。目前, 国外 经典的废弃地景观再造修复案例有:德国鲁尔区北杜伊斯堡景观公园、美国西雅图煤气厂公园、巴西圣保罗市 西维塔公园等; 我国经典案例有:上海世博会后滩公园、上海辰山植物园矿坑花园、中山岐江公园、首钢工业遗 址公园等。

\section{2 城市生态系统修复研究的问题和不足}

\section{1 以人工修复为主, 自然修复不足}

国内外大量研究表明,人工修复短期效果明显快于、好于自然修复,但从长期来看, 人工修复运维成本高, 稳定性、演替效果、生物多样性等方面远不及自然修复 ${ }^{[87-90]}$ 。在湿地修复中, 美国、欧洲、日本等发达国家和 地区提出 “多自然型河流”、“重新自然化”等保护和修复策略, 以及 “让大自然修复湿地” [91] 等思想,将城市地 区过于人工化的湿地环境进行自然化、野化的修复, 目标是修复城市湿地的自然风貌和功能; 废弃地生态修复 中已开始注重利用自然演替以及污染物自然分解等过程实现低干预、低投人和长效的生态修复。如修复过程 中选用乡土植物、利用林下表土和调落物促进自然演替 等 $^{[63]}$; 美国的矿山修复使用一种地貌复等法 (Geomorphic Reclamation), 通过模拟自然的地形地貌、水文过程等,起到了很好的人工促进自然修复效果 ${ }^{[63]}$ 。 但总体而言, 国内的城市生态修复目前仍以人工措施为主,生态系统结构简单、修复效果较差, 甚至常有不当 的人工措施引起生态系统破坏的现象 ${ }^{[92]}$, 需要加强自然修复的研究和应用, 因地制宜, 进行近自然绿地和湿 地的营造和管理。

\section{2 生态修复机理和量化研究不够深人}

当前, 国内外对于城市绿地、湿地、废弃地等生态系统的退化和发展影响机制已逐步从定性转向定量研 究, 在生态系统服务定量研究、结构与功能的量化关系、不同因子的影响机制和程度等方面已取得了一些深人 的研究成果, 但还需继续加强 ${ }^{[93-94]}$ 。且当前的研究中量化分析多以自然因子为主, 对社会因子和经济因子的 研究多为定性分析 ${ }^{[95]}$ 。

\section{3 生态修复理论研究与应用脱节}

城市生态系统修复具有较强应用性, 当前城市生态修复的理论研究取得了许多成果,生态资产评估、自然 保护、环境治理等多方面的研究成果正逐步纳人政府实际决策,然而仍存在理论研究与应用脱节的现象。例 如, 当前我国城市绿地在实际的城市绿地规划、建设、管理中多数仍沿用以往城市园林绿地的方法、指标等,强 调城市绿地的景观、游憩功能, 而对城市绿地解决城市环境问题以及改善居民生活方面应用不足 ${ }^{[96]}$ 。

2.4 管理机制尚不健全

发达国家在城市废弃地管理方面机制比较健全,在管理机构、法律法规、标准规范、资金保障等方面均处 于领先。以美国为例, 美国城市湿地管理的 “零净损失”、湿地补偿银行等制度值得我国借鉴, 以保障城市湿 地总量的稳定 ${ }^{[51]}$ 。在废弃地修复方面, 美国建立了由联邦政府、州政府、地方政府和社区以及社会组织组成 
的多方、多级管理组织 ${ }^{[97]}$; 出台了《超级基金法》、《自愿清理计划》等系列法律法规专门保障废弃地修复; 在 生态修复费用方面,采取“污染者付费”为主,相关责任主体分担的责任方式,同时还设置了生态修复保证金 制度, 调动了污染企业生态修复的积极性 ${ }^{[63]}$ 。相比之下, 我国城市生态修复的管理机制还有较大差距。例 如: 我国以前没有国家层面的湿地立法, 存在管理部门混乱、公众参与程度低等问题 ${ }^{[57]}$, 但是, 国家《湿地保护 法草案》即将出台, 将为湿地保护、修复和管理提供法治保障; 城市湿地的生态补偿制度尚在探索阶段, 已成 为当前湿地保护的制约因素 ${ }^{[94]}$; 废弃地生态修复管理机制尚不够完善,存在法规政策不完善、职责部门不明 确、修复标准不清等问题, 叒待强化完善 ${ }^{[59]}$ 。

2.5 复合生态系统理论体现不足

城市生态系统修复是一个自然-经济-社会复合生态系统的共轭修复。当前,生态修复较多关注生态要素 和过程的修复,而对经济、社会要素和过程重视程度不高,复合价值未得到充分发掘。例如,我国在城市绿地 的修复管理中,景观游䟤仍是着重关注的方面,对“景观特色”、“人性化设计”、“案例分析”等研究较多,而关 于城市绿地对生态环境和居民生活的影响关注较少 ${ }^{[27]}$ 。相比之下, 国外对于城市绿地除了景观游憩功能之 外,十分注重城市绿地的生态环境功能和社会经济功能,着重从“人和绿地关系”、“绿地对生态环境的影响” 等方面开展了许多深人研究, 形成了定量结合定性的研究范式, 且定量研究有不断增多的趋势 ${ }^{[98]}$ 。

\section{3 城市生态系统修复研究的热点}

\section{1 城市生态系统修复的机理}

机理研究是理解、推动和深化城市生态系统修复研究和实践的基础。主要热点有城市绿地、湿地、废弃地 生态环境问题的作用和调控机理、城市生态系统的演替机理、城市生态格局的演变及影响机制、复合生态系统 理论与城市生态修复的耦合机制等方面。

\section{2 城市生态资产与生态系统服务}

城市生态资产包括自然资源资产和生态系统服务,是评估生态修复效果和开展生态补偿等工作的重要基 础。城市生态系统服务是城市生态修复研究的核心, 也是最根本的落脚点。城市生态系统和自然生态系统具 有明显差异性, 今后的研究热点将更加关注与城市居民相关的生态系统服务。城市生态系统服务的指标体 系、生态资产实物量和价值量的评估与核算方法、生态系统服务的权衡等也是今后的研究热点。

\section{3 城市生态系统质量和健康}

城市生态系统的质量和健康是发挥复合生态效益的基础,生态修复的本质是生态系统质量的提升。在城 市绿地生态系统修复方面, 今后将从传统园林绿化更关注视觉景观效果转变为提升绿地生态系统的质量和稳 定性。主要热点有强化对乡土树种、植被区系、地带性植被特征、生物多样性等自然要素的研究,以及城市绿 地的自然修复、近自然经营等途径。城市湿地质量和健康的研究热点有:通过水资源、水质、生态系统的调控, 保障城市湿地系统的健康; 通过保护乡土植物、构建生物栖息地、生态廊道等保护城市湿地生物多样性。

\section{4 问题导向的城市生态系统修复}

城市生态系统具有明显不同于自然生态系统的特征, 针对典型城市问题开展生态系统修复研究有助于更 好开展城市生态系统的保护和建设。主要热点有城市绿地的数量、结构、布局与城市的生物多样性、微气候、 雨洪管理等方面的作用机制和量化关系,尤其是加强对热岛效应、生境破碎、生物多样性丧失、空气污染等突 出城市问题的机理和应对措施研究; 城市化及城市环境对城市湿地的影响机制; 城市湿地对城市生态安全、城 市生态环境等的影响; 城市湿地与热岛效应、空气污染等城市问题的联系; 城市湿地与居民生活、生态文化科 普教育等的联系等。

\section{5 面向人类福祉的城市生态系统修复}

以人为本, 以居民福祉作为导向, 注重与生态学、社会学、城市学、经济学、管理学、医学等多学科的交叉, 研究城市绿地、湿地对居民身心健康、景观游憩、自然教育、防灾减灾、森林康养、幸福感、犯罪率、环境正义等 
方面的影响机制,以及老人、儿童等特殊群体对城市绿地、城市湿地的需求等。

3.6 城市生态系统修复的多学科融贯

城市生态系统的保护、修复、管理具有多目标、多属性、多主体的特征。当前城市生态系统修复的研究主 要集中于生态学、风景园林学、环境工程学、水文学等学科交叉领域, 今后研究的热点是与城市规划学、管理 学、社会学、经济学、地理学等学科的充分融合,构建多学科融贯的理论体系和自然、经济、社会子系统协调的 运行机制。

3.7 新方法和新技术的研究与应用

新方法和新技术的研究与应用是城市生态修复实践的重要基础工作。以城市废弃地为例, 今后的研究热 点包括以自然-经济-社会复合生态系统理论为基础,探索地区性的废弃地修复规划方法; 运用景观生态学方 法, 探索系统性和大尺度的废弃地生态系统修复和规划途径; 加强生态修复新方法和新技术研究,如生态修复 监测技术、植物修复的全过程技术、土壤的微生物修复技术、乡土物种保持、特定污染的土壤修复技术等。

\section{4 讨论和总结}

城市生态系统修复是自然-经济-社会的共轭修复。在城市绿地、城市湿地、城市废弃地的修复中,应调节 好自然、社会、经济过程,在修复理念、工程技术、调查、评估、规划、管理等方方面面均要以复合生态系统理论 为指导, 促进城市复合生态系统的各方面协同高效可持续发展。当前,随着我国城镇化速度的逐步放缓以及 城市开发边界、基本农田、生态红线等系列政策的落实,城市建设用地和生态用地的规模、范围已逐步确定。 基于复合生态系统理论开展城市绿地、湿地、废弃地的生态系统修复, 提升有限空间内的复合生态价值对于城 市和城市居民来说意义更加深远。

国内外以城市绿地、湿地、废弃地为切人点,已开展了许多研究, 取得了丰富的研究和实践成果。但总体 来说, 城市生态系统修复的理论体系尚有待进一步完善。一方面,复合生态系统理论在城市生态修复中的指 导地位尚没有充分体现, 许多城市生态系统修复的研究仅以单一自然过程或局部价值作为衡量标准, 缺乏自 然、经济和社会的统筹考虑; 另一方面, 城市生态系统修复的机理研究尚待深人, 尤其是自然过程与经济、社会 过程的耦合机制以及定量化、动态化、多尺度的研究, 将是今后的研究重点。目前我国城市生态系统修复研究 和应用虽然取得许多成果, 但与问题导向和发展目标等多方面还有一定差距, 今后在开展城市生态系统修复 的研究和实践的过程中,需要统筹关注以下几个方面:

(1) 注重生态优先。在城市生态系统中, 自然过程是经济、社会过程的基础, 因此城市生态系统修复研究 和实践中,应当理顺自然、经济、社会三者的逻辑关系, 以生态过程的修复为基础, 尤其是城市典型的生态环境 问题,需得到充分重视, 只有健康稳定的生态系统才能持续支撑城市经济和社会的长远发展。

(2) 注重公众参与。城市生态系统修复研究和实践中需探索科学合理的公众参与机制, 同时注重平衡多 数人和少数人、一般人群和特殊群体之间的关系, 协调政府、企业、社会组织、居民间的关系, 形成多元的参与、 决策、评判和监督机制等。

(3) 注重合理权衡。从宏观尺度来说, 城市生态系统修复应以追求生态系统服务价值的最大化为总目 标, 但在具体的节点修复中, 由于不同场地自然、经济、社会条件的空间特性差异,往往不能以 “最大化” 作为 修复目标, 而是追求 “最优化”。今后研究中应注重合理权衡生态系统修复的主要功能和次要功能, 探索目标 制定和价值权衡的原则与方法。

(4) 注重生态管理。注重城市生态系统修复管理方法和机制的研究, 以推动形成完善高效的管理机制; 还需注重法律法规、标准、指南、规范等的研究和制定, 使研究成果尽快与国家、地方、行业和团体等管理体系 相互衔接。

\section{参考文献 ( References) :}

[1] 马世骏, 王如松. 社会-经济-自然复合生态系统. 生态学报, 1984, 4(1) : 1-9. 
[2 ] 李锋, 王如松. 城市绿地系统的生态服务功能评价、规划与预测研究——以扬州市为例. 生态学报, 2003, 23(9): 1929- 1936.

[ 3 ] 孟伟庆, 李洪远, 朱琳, 陈小奎. 城市绿化的发展思路——绿色空间建设. 城市环境与城市生态, 2005, 18(2): 8-10.

[ 4 ] 赵晶, 朱霞清. 城市公园系统与城市空间发展—19 世纪中叶欧美城市公园系统发展简述. 中国园林, 2014, 30(9): 13-17.

[ 5 ] 郑宾. 2/3 地球资源被严重破坏一一解读《千年生态系统评估》报告. 科学生活, 2005, (5): 11-13

[ 6 ] Nilsson K, Konijnendijk C C, Nielsen A B. Urban forest function, design and management//Meyers R A, eds. Encyclopedia of Sustainability Science and Technology. New York: Springer, 2012.

[ 7 ] Bowler D E, Buyung-Ali L, Knight T M, Pullin A S. Urban greening to cool towns and cities: a systematic review of the empirical evidence. Landscape and Urban Planning, 2010, 97(3) : 147-155.

[ 8 ] Rupprecht C D D, Byrne J A. Informal urban greenspace: a typology and trilingual systematic review of its role for urban residents and trends in the literature. Urban Forestry \& Urban Greening, 2014, 13(4) : 597-611.

[ 9 ] Lee A C K, Maheswaran R. The health benefits of urban green spaces: a review of the evidence. Journal of Public Health, 2011, 33(2) : 212-222.

[10] White M P, Alcock I, Wheeler B W, Depledge M H. Would you be happier living in a greener urban area? A fixed-effects analysis of panel data. Psychological Science, 2013, 24(6) : 920-928.

[11] 杨学军, 唐东芹, 许东新, 王新华, 潘高红. 上海地区绿化树种重金属污染防护特性的研究. 应用生态学报, 2004, 15(4): 687-690.

[12] 谢滨泽. 城市绿地植物叶表面微结构及配置方式对其滞留 $\mathrm{PM}_{2.5}$ 等颗粒物的影响 $[\mathrm{D}]$. 西安: 西安建筑科技大学, 2015.

[13］陈珂珂, 何瑞珍, 梁涛，田国行. 基于“海绵城市”理念的城市绿地优化途径. 水土保持通报, 2016, 36(3): 258-264.

[14] 方凌波, 金云峰. 从棕地到绿地一一基于污染物治理的 GROs 风险管理策略研究//中国风景园林学会会 2016 年会论文集. 北京: 中国建 筑工业出版社, 2016.

[15] Kubota T, Lee H S, Trihamdani A R, Phuong T T T, Tanaka T, Matsuo K. Impacts of land use changes from the Hanoi Master Plan 2030 on urban heat islands: Part 1. Cooling effects of proposed green strategies. Sustainable Cities and Society, 2017, 32: 295-317.

[16] Park J, Kim J H, Lee D K, Park C Y, Jeong S G. The influence of small green space type and structure at the street level on urban heat island mitigation. Urban Forestry \& Urban Greening, 2017, 21: 203-212.

[17］吴丽娟. 北京城市绿地景观格局与生物多样性保护研究 [D ]. 北京: 北京林业大学, 2006.

[18］陈爱莲, 孙然好, 陈利顶. 绿地格局对城市地表热环境的调节功能. 生态学报, 2013, 33(8): 2372-2380.

［19］屠星月, 黄甘霖, 邬建国. 城市绿地可达性和居民福祉关系研究综述. 生态学报, 2019, 39(2): 421-431.

[20］张云路, 李雄. 基于供给侧与需求侧视角下的城市绿地系统规划与城市发展互动关系思考//中国风景园林学会 2016 年会论文集. 北京: 中国建筑工业出版社, 2016 .

［21］兰思仁, 李霄鹤, 彭东辉, 余韵. 城市建设中的生物多样性及其保育对策. 中国城市林业, 2013，11(5): 10-13.

[22]申世广, 王浩, 荚德平, 谷康. 基于 GIS 的常州市绿地适宜性评价方法研究. 南京林业大学学报(自然科学版), 2009, 33(4)：72-76.

[23］吴泽民. 城市森林经营管理中的几个主要方面. 中国城市林业, 2005, 3(5): 17-19.

[24] 王成. 近自然的设计和管护——建设高效和谐的城市森林. 中国城市林业, 2003, 1(1): 44-47.

[25] Tan P Y, Samsudin R. Effects of spatial scale on assessment of spatial equity of urban park provision. Landscape and Urban Planning, 2017, 158: 139- 154 .

[26] 唐子来, 顾姝. 再议上海市中心城区公共绿地分布的社会绩效评价: 从社会公平到社会正义. 城市规划学刊, 2016, (1) : 15-21.

[27] 陈春娣, Douglas M C, 吴胜军, 陈吉龙, 刘峰. 城市湿地景观格局与生态一一社会过程研究进展. 湿地科学与管理, 2014, (1) : 57-61.

[28］李春轫, 郑小康, 牛少凤, 蔡宴朋, 沈楠, 庞爱萍. 城市湿地保护与修复研究进展. 地理科学进展, 2009, 28(2): 271-279.

[29] Lee S Y, Dunn R J K, Young R A, Connolly R M, Dale P E R, Dehayr R, Lemckert C J, Mckinnon S, Powell B, Teasdale P R, Welsh D T. Impact of urbanization on coastal wetland structure and function. Austral Ecology, 2006, 31(2) : 149-163.

[30] Faulkner S. Urbanization impacts on the structure and function of forested wetlands. Urban Ecosystems, 2004, 7(2) : 89- 106.

[31］庞丙亮. 湿地生态系统服务价值评价的去重复性计算研究 [D]. 北京: 中国林业科学研究院, 2014.

[32] 吴旭阳. 城市湿地生态修复的界面空间模式研究 [D ]. 北京: 清华大学, 2015.

[33] Xue Z S, Hou G L, Zhang Z S, Lyu X G, Jiang M, Zou Y C, Shen X J, Wang J, Liu X H. Quantifying the cooling-effects of urban and peri-urban wetlands using remote sensing data: Case study of cities of Northeast China. Landscape and Urban Planning, 2019, 182: 92-100.

[34] Zhu C Y, Zeng Y Z. Effects of urban lake wetlands on the spatial and temporal distribution of air $\mathrm{PM}_{10}$ and $\mathrm{PM}_{2.5}$ in the spring in Wuhan. Urban Forestry \& Urban Greening, 2018, 31: 142-156.

[35] Yan G X, Liu J K, Zhu L J, Zhai J X, Cong L, Ma W M, Wang Y, Wu Y N, Zhang Z M. Effectiveness of wetland plants as biofilters for inhalable particles in an urban park. Journal of Cleaner Production, 2018, 194: 435-443.

[36] Liu J K, Yan G X, Wu Y N, Wang Y, Zhang Z M, Zhang M Y. Wetlands with greater degree of urbanization improve PM2.5 removal efficiency. Chemosphere, 2018, 207: 601-611. 
[37] Huang Y, Liu J, Wang J, Xie Y N. How urban wetland-based environmental education activate school children's childhoodnature in anthropocene times: experience from Chinese curriculum reform//Cutter-Mackenzie-Knowles A, Malone K, Hacking E B, eds. Research Handbook on Childhoodnature: Assemblages of Childhood and Nature Research. Cham: Springer, 2019: 1-13.

[38] Pedersen E, Weisner S E B, Johansson M. Wetland areas' direct contributions to residents' well-being entitle them to high cultural ecosystem values. Science of the Total Environment, 2019, 646: 1315-1326.

[39] Du X J, Huang Z H. Spatial and temporal effects of urban wetlands on housing prices: Evidence from Hangzhou, China. Land Use Policy, 2018, 73: 290-298.

[40] Vymazal J. The use of hybrid constructed wetlands for wastewater treatment with special attention to nitrogen removal: a review of a recent development. Water Research, 2013, 47(14): 4795-4811.

[41] 尹炜, 李培军, 尹澄清, 台培东, 李海波, 郭伟. 潜流人工湿地的局限性与运行问题. 中国给水排水, 2004, 20(11): 36-38.

[42] 高志勇, 谢恒星, 李吉锋, 刘史力. 人工湿地处理污水研究进展. 渭南师范学院学报, 2018, 33(8): 16-21.

[43] 许春华, 周琪, 宋乐平. 人工湿地在农业面源污染控制方面的应用. 重庆环境科学, 2001, 23(3): 70-72.

[44] 贵天虎, 朱卫东. 人工湿地生活污水处理技术试验研究. 黄河水利职业技术学院学报, 2014, 26(3): 10-13.

[45] Hale R, Swearer S E, Sievers M, Coleman R. Balancing biodiversity outcomes and pollution management in urban stormwater treatment wetlands. Journal of Environmental Management, 2019, 233: 302-307.

[46] Dou T T, Troesch S, Petitjean A, Gábor P T, Esser D. Wastewater and rainwater management in urban areas: a role for constructed wetlands. Procedia Environmental Sciences, 2017, 37: 535-541.

[47] 李洁, 崔丽娟, 李伟, 王小文, 马牧源, 张曼胤. 兼顾景观功能的人工湿地植物配置模式探讨. 湿地科学与管理, 2013, 9(1): 10- 14.

[48] 邹锦. 人工湿地生态景观设计 [D]. 重庆: 重庆大学, 2005.

[49] 张颂, 刘学燕, 王利军. 复合型人工湿地技术在永定河生态修复中的应用研究//科技创新与水利改革一一国水利学会 2014 学术年会 论文集. 南京: 河海大学出版社, 2014.

[50] 黄时达, 王庆安, 钱骏, 任勇. 从成都市活水公园看人工湿地系统处理工艺. 四川环境, 2000, 19(2): 8-12.

[51] 刘金氷, 孙飞翔, 李丽平. 美国湿地补偿银行机制及对我国湿地保护的启示与建议. 环境保护, 2018,46(8): 75-79.

[52］张倩. 浅析国外湿地保护立法对我国的启示. 江西农业学报, 2011, 23(2): 190-192.

[53］郡琛霞. 从保护到经营: 美国湿地保护交易制度及其启示. 中国土地科学, 2014, 28(1) : 68-74.

[54] 吕咏, 陈克林. 国内外湿地保护与利用案例分析及其对镜湖国家湿地公园生态旅游的启示. 湿地科学, 2006, 4(4): 268-273.

[55] 朴希桐, 李婷婷, 聂俊坤. 城市湿地生态规划方略研究. 中国水利, 2019, (13) : 20-23.

[56] 李益敏, 李卓卿. 国内外湿地研究进展与展望. 云南地理环境研究, 2013, 25(1): 36-43.

[57] 雷昆, 张明祥. 中国的湿地资源及其保护建议. 湿地科学, 2005, 3(2) : 81-86.

[58] 彭静. 城市废弃地生态修复与景观再造模式研究 $[\mathrm{D}]$. 武汉: 中国地质大学, 2018.

[59］郑晓笛. 基于 “棕色土方” 概念的棕地再生风景园林学途径 [D]. 北京: 清华大学, 2014.

[60］梁欣. 旧厂房改造土壤重金属污染的原位与异位修复技术进展. 中国资源综合利用, 2018, 36(5): 85-87.

[61］冯俊生, 张俏晨. 土壤原位修复技术研究与应用进展. 生态环境学报, 2014, 23(11): 1861-1867.

[62] 姜林, 龚宇阳. 场地与生产设施环境风险评价及修复验收手册. 北京: 中国环境科学出版社, $2011: 155$.

[63] 张绍良, 米家金金, 侯湖平, 杨永均. 矿山生态恢复研究进展一一基于连续三届的世界生态恢复大会报告. 生态学报, 2018, 38( 15) : 5611-5619.

[64] 关军洪, 郝培尧, 董丽, 李雄. 矿山废弃地生态修复研究进展. 生态科学, 2017, 36(2)：193-200.

[65] 赵玉洁, 张宇清. 固氮类植物的生态功能及其在生态修复中的应用. 干旱区资源与环境, 2012, 26(1)：179-183.

[66] Luo J, Qi S H, Gu X W S, Wang J J, Xie X M. Evaluation of the phytoremediation effect and environmental risk in remediation processes under different cultivation systems. Journal of Cleaner Production, 2016, 119: 25-31.

[67] Boldt-Burisch K, Naeth M A, Schneider B U, Hüttl R F. Linkage between root systems of three pioneer plant species and soil nitrogen during early reclamation of a mine site in Lusatia, Germany. Restoration Ecology, 2015, 23(4) : 357-365.

[68] Chibuike G U, Obiora S C. Heavy metal polluted soils: effect on plants and bioremediation methods. Applied and Environmental Soil Science, 2014, 2014: 752708 .

[69] Su C, Jiang L Q, Zhang W J. A review on heavy metal contamination in the soil worldwide: Situation, impact and remediation techniques. Environmental Skeptics and Critics, 2014, 3(2): 24-38.

[70] 郭洋楠. 神东矿区水土保持植物区系分析. 水土保持通报, 2016, 36(2): 260-263.

[71] 林武星, 陈东华, 倪志荣, 谭芳林, 曾国强, 朱炜. 闽南沿海石矿区植物配置模式对水土保持的影响. 防护林科技, 2006, (4): 1-3.

[72] 孙月美, 宁国辉, 刘树庆, 王倩倩, 杨树深, 杨志新. 耐受性植物油葵和棉花对镉的富集特征研究. 水土保持学报, 2015, 29(6): 
281-286.

[73] 高洁, 周永刚, 张琪, 张冬梅, 鲁琳. 污泥耐受性草本植物的篮选及其对重金属 Cu、Zn 的富集. 环境工程学报, 2013, 7(1): 351-359.

[74] 杨翠霞, 张成梁, 刘禹伯, 郑艳. 矿区废弃地近自然生态修复规划设计. 江苏农业科学, 2017, 45(17): 269-272.

[75] Nussbaumer Y, Cole M A, Offler C E, Patrick J W. Identifying and ameliorating nutrient limitations to reconstructing a forest ecosystem on mined land. Restoration Ecology, 2016, 24(2) : 202-211.

[76] 李子海. 植被恢复中存在的一些生态学理论应用误区. 环境科学导刊, 2008, 27(S1) : 72-73.

[77］陈芳清, 卢斌, 王祥荣. 樟村坪磷矿废弃地植物群落的形成与演替. 生态学报, 2001, 21(8): 1347-1353.

[78] Holl K D. Long-term vegetation recovery on reclaimed coal surface mines in the eastern USA. Journal of Applied Ecology , 2002, 39(6) : 960-970.

[79] 郭逍宇, 张金屯, 宫辉力, 张桂莲, 董志. 安太堡矿区复旺地植被恢复过程多样性变化. 生态学报, 2005, 25(4) : 763-770.

[80］孙一琳, 田涛, 赵廷宁, 杨建英. 矿山废弃地植被恢复技术模式初步研究一以北京周边矿山为例//全国工程绿化技术交流研讨会论文 集. 贵阳: 中国水土保持学会, 2008.

[81］陈法扬. 生态修复与可持续发展//全国水土保持生态修复研讨会论文集.北京: 水利部, 中科院资源环境科学与技术局 2004.

［82］袁清超, 牛首业, 赵廷华, 牛晓繁, 郭红超. 石质边坡防护中生态植被延水土保持效果研究. 人民长江, 2017, 48(17): 34-36.

[83] Stewart K M E, Penlidis A. Designing polymeric sensing materials for analyte detection and related mechanisms. Macromolecular Symposia, 2016, $360(1): 123-132$.

[84] Borkenhagen A, Cooper D J. Creating fen initiation conditions: a new approach for peatland reclamation in the oil sands region of Alberta. Journal of Applied Ecology, 2016, 53(2): 550-558.

[85] Sizmur T, Martin E, Wagner K, Parmentier E, Watts C, Whitmore A P. Milled cereal straw accelerates earthworm (Lumbricus terrestris) growth more than selected organic amendments. Applied Soil Ecology, 2017, 113: 166-177.

[86] 郭少锋. 城市工业废弃地生态修复与更新思路初探 [D]. 天津: 天津大学, 2007.

[87] 刘世忠, 夏汉平, 孔国辉, 敖惠修, 邓钊平, 柯宏华, 李丽华, 谭鹏. 茂名北排油页岩废渣场的土壤与植被特性研究. 生态科学, 2002,21 (1) : 25-28.

[88] Hodačová D, Prach K. Spoil heaps from brown coal mining: technical reclamation versus spontaneous revegetation. Restoration Ecology, 2003 , 11 (3) : 385-391.

[89] Pensa M, Sellin A, Luud A, Valgma I. An analysis of vegetation restoration on opencast oil shale mines in Estonia. Restoration Ecology, 2004, 12 (2) : 200-206.

[90] Burton C M, Burton P J, Hebda R, Turner N J. Determining the optimal sowing density for a mixture of native plants used to revegetate degraded ecosystems. Restoration Ecology, 2006, 14(3) : 379-390.

[91] Cally J, 刘丛. 让大自然修复湿地. 环球科学, 2014, (1): 48-53.

[92］张毅川, 乔丽芳, 陈亮明. 城市湿地公园景观建设研究. 重庆建筑大学学报, 2006, 28(6)：18-23.

[93] 吴辉, 邓玉林, 李春艳, 郭朝霞. 我国湿地研究、保护与开发. 世界林业研究, 2007, 20(6) : 42-49.

[94] 王昌海, 崔丽娟, 毛旭锋, 温亚利. 湿地保护区周边农户生态补偿意愿比较. 生态学报, 2012, 32(17): 5345-5354.

[95］段皓严, 张沛, 薛立尧. 基于共词聚类分析的国内外街旁绿地研究前沿比较及创新思考. 中国园林, 2019, 35(2) : 69-74.

[96］常青, 李双成, 李洪远, 彭建, 王仰麟. 城市绿色空间研究进展与展望. 应用生态学报, 2007, 18(7) : 1640- 1646.

[97］苏飞, 张平宇. 欧美国家城市工业废弃地治理及其启示. 国际城市规划, 2007, 22(4): 71-74.

[98］王俊帝, 刘志强, 郡大伟, 余慧. 基于 CiteSpace 的国外城市绿地研究进展的知识图谱分析. 中国园林, 2018, 34(4): 5-11. 